\title{
História e Filosofia da Ciência: investigação documental para a formação de professores de ciências
}

\section{History and Philosophy of Science: documentary research for the education of science teachers}

\author{
Scarlett Aldo de Souza Favorito ${ }^{1}$, Elisabete Alerico Gonçalves ${ }^{2}$, Paulo Vitor Teodoro ${ }^{3 *}$
}

\begin{abstract}
RESUMO
A pesquisa objetivou-se promover uma análise nos Currículos dos Campis de uma Instituição de Ensino Superior (IES) os quais possuem Cursos de Licenciatura em Química/Ciências, verificando a existência e relevância das disciplinas que aborda a História e Filosofia das Ciências (HFC). A pesquisa desenvolvida é de cunho qualitativo, com investigação documental. Como fundamentação teórica, utilizou-se a pesquisa bibliográfica. Os procedimentos metodológicos dividiu a pesquisa em quatro etapas, sendo: 1) Levantamento dos Campis da IES que possuem o curso de Licenciatura em Química; 2) Solicitação, aos Coordenadores, da autorização para a realização da pesquisa e disponibilização dos Projetos Pedagógicos dos Cursos (PPCs); 3) Análise e verificação da existência e relevância das disciplinas de HFC na Matriz Curricular; 4) Elaboração e envio de questionário por meio da plataforma do Google, para os professores dos campis da IES. Depois da análise, concluímos que os cursos possuem escassas disciplinas efetivamente voltadas a HFC, e que os docentes não foram preparados em suas graduações. Além disso, mesmo os que já trabalharam com a HFC, sentem dificuldades em ministrá-las. Percebeu-se que é emergente a necessidade de repensar os currículos, melhorando a concepção e relevância sobre as disciplinas de HFC a fim de promover melhor preparo dos futuros docentes.
\end{abstract}

Palavras-chave: História e Filosofia da Ciência; Formação de professores; Ensino.

\footnotetext{
ABSTRACT

The research aims to promote an analysis of the Curriculum of Campuses of a Higher Education Institution (IES, in Portuguese/Brazil) which have Degree Courses in Chemistry/Science, verifying the existence and relevance of the disciplines that address the History and Philosophy of Science (HFC). The research developed is of a qualitative nature, with documentary research. As a theoretical foundation, bibliographic research was used. The methodological procedures divided the research into four stages, as follows: 1) Survey of IES Campuses that have the Degree in Chemistry; 2) Request, from the Coordinators, authorization to carry out the research and make available the Pedagogical Projects of the Courses (PPCs); 3) Analysis and verification of the existence and relevance of HFC subjects in the Curriculum Matrix; 4) Elaboration and sending of a questionnaire through the Google platform, for the

1,2 Instituto Federal de Educação, Ciência e Tecnologia Goiano (IF Goiano).

${ }^{3}$ Universidade Federal de Uberlândia (UFU)/ Programa de Pós-Graduação (Stricto Sensu) em

Ensino de Ciências e Matemática/UFU.

*E-mail do autor responsável pela submissão: paulovitorteodoro@ufu.br
} 
professors of the IES campuses. After the analysis, we concluded that the courses have few subjects effectively focused on HFC, and that the professors were not prepared in their graduations. In addition, even those who have already worked with the HFC, find it difficult to administer them. It was noticed that there is an emerging need to rethink curricula, improving the design and relevance of HFC disciplines in order to promote better preparation of future teachers.

Keywords: History and Philosophy of Science; Teacher training; Science teaching.

\section{INTRODUÇÃO}

Ao estudar a formação inicial dos professores, consideramos que os cursos de licenciatura exigem criticidade em sua proposição, principalmente nos componentes curriculares inerentes ao desempenho do docente, como as disciplinas ligadas a filosofia e história da ciência (HFC). Essas disciplinas dão subsídios ao futuro docente aprimorando os conhecimentos necessários para ministrar determinados conteúdos. Além disso, auxiliam na forma com que o professor irá transpor esses conteúdos a seus alunos, uma vez que estão presentes no contexto das ciências, desde seu surgimento. Então, se o papel do professor é levar os alunos a refletirem sobre a origem e aplicabilidade do que se está ensinando é imprescindível que, durante a formação do professor de química, conheça, pelo menos a história do que vai ensinar (MARQUES, 2015).

É nesse sentido que o conhecimento dos aspectos históricos tornasse promissor para o ensino. Além de conhecer a matéria que ensina, é importante ao professor conhecer a história daquilo que ensina [...] cuja relevância não pode ser desprezada, uma vez que tratam de um conhecimento que era pertinente e necessário na época em que foi pensado (MARQUES, 2015, p. 6).

Como confirmam também Labarrere e Quintanilla (2002) apud Fernández, Gatica e Blancafort (2010),

[...] o ensino da química embasada em uma perspectiva histórica, em que adquire importância no desenho de unidades de ensino que incorporam os aspectos envolvidos na gênese e evolução dos conceitos científicos, permitirá dimensionar o caráter problematizador do ensino e da aprendizagem das ciências [...] (LABARRERE e QUINTANILLA, 2002 apud FERNÁNDEZ, GATICA e BLANCAFORT, 2010, p. 281).

O conhecimento histórico da ciência é necessário no meio escolar. Ao abordar a história das ciências apresenta-se ao alunado as suas contribuições para a formação 
científica atual. É a evolução dos conceitos científicos, consolidando essas realizações e trazendo legitimidade para a área de pesquisa.

Mas a história da química não deve ser ministrada de uma forma qualquer, só pontuando as revoluções no decorrer dos anos no meio científico. Segundo Penitente e Castro (2010),

[...] o conhecimento construído ao longo dos séculos passa por um processo de transformação, portanto, ele deve ser acessível, tangível e possível, sem deixá-lo cair na banalização. No entanto, isso só será possível se o professor e a professora souberem auxiliar o aluno e a aluna a transformarem seu sistema cognitivo, favorecendo sua aprendizagem e proporcionando a ambos os desafios, apontando lacunas e aproximando níveis de compreensão e ação [...] (PENITENTE; CASTRO, 2010, p. 235).

Levar para a sala de aula a dimensão histórica assume uma importância muito significativa, uma vez que os alunos constroem historicamente o que conhecem. Nesse sentido, o conteúdo parece se tornar mais atrativo e mais próximo do universo dos alunos.

Mas não é só a história das ciências que é importante no processo de ensino e aprendizagem; a filosofia também é imprescindível para a formação do futuro docente, visto que é voltada para a discussão de problemas fundamentais. É sempre associada aos valores éticos e morais (SILVA; SOBREIRA; ABREU, 2017).

A filosofia também proporciona a reflexão sobre as ciências, como afirma Adúriz-Bravo; Isquierdo e Estany (2002):

[...] a filosofia da ciência tem um valor específico, como reflexão teórica (ou seja, por meio dos modelos) sobre a ciência. Este valor específico complementa e reforça o conteúdo científico fornecendo uma imagem adicional dinâmica, completa, e menos normativo e dogmático, da científica [...] (ADÚRIZ-BRAVO; ISQUIERDO; ESTANY, 2002, p. 468).

Dado o exposto, a necessidade de relacionar a filosofia com a ciência, permite que o aluno entenda melhor os conteúdos e adquira um senso crítico e reflexivo. Além disso, a filosofia da ciência pode contribuir no ensino-aprendizagem do conteúdo científico, propondo uma maior fundamentação para o ensino de ciências.

A utilização da HFC torna as aulas de ciências mais desafiadoras e interessantes. Permite que os alunos possam desenvolver um pensamento crítico, contribuindo para a superação da falta de significação dos conteúdos ministrados, proporcionando assim, maior compreensão por mostrar a importância da disciplina para seu aprendizado. 
Além disso, a FC permite à $\mathrm{HC}$, entender melhor as relações que são estabelecidas entre as várias ações que convergem na atividade de "fazer ciência". Como alegou Imre Lakatos (1987 apud IZQUIERDO-AYMERICH; ADÚRIZ-BRAVO et.al. 2016, p.15), “a história sem filosofia é cega, e filosofia sem história está vazia”.

A filosofia e a história auxiliam na produção de conhecimento científico DC das ciências também é um componente imprescindível para a formação docente, como afirma Lopes (2007).

A organização do conhecimento em disciplinas e os processos de mediação didática a ela associados, são modificadores do conhecimento científico e constitutivo de um conhecimento propriamente escolar.

Segundo Gonçalves (2017), existe uma relação entre a filosofia, história das ciências com a didática das ciências:

A relação da filosofia das ciências com a história e a didática das ciências fica em destaque por proporcionar uma maior reflexão sobre os procedimentos de ensino e da própria aprendizagem necessárias à organização dos currículos educacionais e dos conhecimentos pertinentes à formação de professores. (GONÇALVES, 2017, p. 5).

A didática das ciências, sem a filosofia e a história, se torna muito superficial. Para transpor conhecimento aos alunos, o conteúdo tem que ser ministrado sem que haja nenhuma distorção, ou seja, devem ser ensinados dentro da complexidade da ciência, em uma linguagem a ser ensinada e a ser compreendida.

A HFC, juntamente com a DC, proporciona fazer essa transposição didática, mantendo-se fiel aos conhecimentos epistemológicos. Com isso, a união HFDC é de suma importância uma vez que estão diretamente interligadas, conforme mostra a figura abaixo.

Figura 1: Tríade da história(H), filosofia(E) e didática(D) das ciências

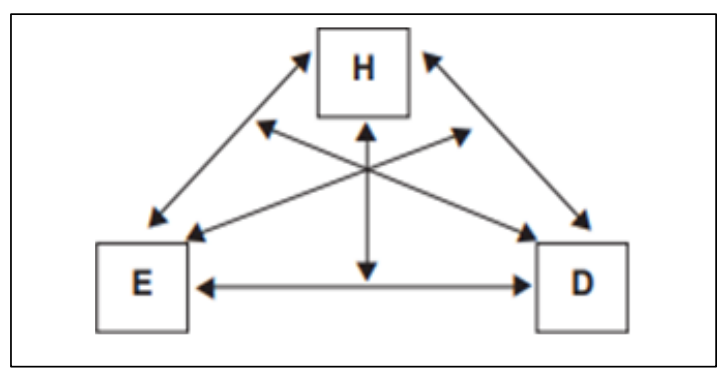

Fonte: Torres e Badillo (2007, p. 94).

Essa tríade é explicada por Torres e Badillo (2007) como sendo, 
[...] A relação entre história (H) e epistemologia (E), é o que determina a partir de qual perspectiva faz a reconstrução histórica e, consequentemente, estipula qual versão dessa história é proposta [...] A história $(\mathrm{H})$ e a relação didática das ciências (D) existirão se, em determinado sistema educacional, a história for considerada imprescindível para um melhor entendimento [...] A relação entre epistemologia (E) e didática (D), em primeiro lugar, requer que didática seja colocada em prática no coletivo da sala de aula. A partir da abordagem empiropositivista e tecnicista, essa didática terá um caráter meramente instrumental, ou seja, reduzida aos métodos de ensino, no contexto usual em que se assume como a parte operadora de pedagogia, em que esta última é considerada, sem melhor análise epistemológica, como a ciência da educação. Se a abordagem é dedutivista-construtivista, a didática será assumida como disciplina conceitual e metodologicamente fundamentada (TORRES; BADILLO, 2007, p. 94).

Portanto, a utilização da HFDC proporciona subsídios para que os conteúdos sejam ministrados de forma mais eficaz. A partir da visão histórica e filosófica da ciência, o docente terá condições para mostrar a origem e a aplicabilidade destes conhecimentos científicos. Como menciona Mattews (1994),

“[...] podem melhorar a formação do professorado, contribuindo para o desenvolvimento de uma epistemologia da ciência mais rica e mais autêntica, isto é, um melhor conhecimento da estrutura da ciência bem como seu lugar no marco intelectual das coisas". (MATTEWS, 1994, p. 256).

Neste aspecto, a didática das ciências torna-se uma ferramenta primordial, pois, quando não utilizada adequadamente, o conhecimento produzido se tornará “[...] um mar sem sentidos" (MATTEWS, 1994, p. 256).

\section{MATERIAIS E MÉTODOS}

A pesquisa desenvolvida é de cunho qualitativo "pesquisa qualitativa não se preocupa com representatividade numérica, mas, sim, com o aprofundamento da compreensão dos dados da pesquisa" (GERHARDT; SILVEIRA, 2009, p. 31), com análise documental que de acordo com Gil (2002, p. 45), "são materiais que não receberam ainda um tratamento analítico, ou que ainda podem ser reelaborados de acordo com os objetos da pesquisa". Como fundamentação teórica utilizou-se a pesquisa bibliográfica que é desenvolvida com base em material já elaborado, constituído principalmente de livros e artigos científicos (GIL, 2002). 
Os procedimentos metodológicos foram organizados em quatro etapas. $\mathrm{Na}$ primeira etapa, realizou-se um levantamento junto a todos os Campis da IES, para verificar a existência do curso de Licenciatura em Química. Para o desenvolvimento da segunda etapa, primeiramente fez-se contato com os coordenadores dos cursos dos Campis que possuíam o curso de licenciatura em química, a fim de solicitar autorização para a pesquisa e a disponibilização dos Projetos Pedagógicos dos Cursos (PPCs) atualizados.

A análise e a verificação da existência das disciplinas de história, filosofia e didática das ciências (HFC/DC) nos PPCs dos Cursos de Licenciatura em Química, contemplam a terceira etapa. Como última e quarta etapa, desenvolveu-se um questionário para ser aplicado aos professores.

O questionário é entendido como sendo um instrumento de coleta de dados, constituído por uma série ordenada de perguntas (LAKATOS e MARCONI, 2003). O mesmo teve a finalidade de verificar o conhecimento e relevância disciplinas, relacionadas à $\mathrm{HFC}$ e $\mathrm{DC}$, como componente curricular para a formação dos professores.

Com a finalidade de ter maior abrangência, o questionário foi elaborado na plataforma Google. Para que os professores dos cursos de Licenciatura em Química pudessem acessá-lo, foi enviado, aos e-mails institucionais, o link com o endereço de acesso. E, como forma de acompanhamento aos docentes que ainda não tinham respondido, enviava-se novos e-mails, semanalmente, relembrando os professores sobre a importância das respostas para a pesquisa.

\section{RESULTADOS E DISCUSSÃO}

Tratar da HFC, "ajuda a concretizar unidades didáticas em que as "verdades" que se buscam não são definitivas. Com o surgimento de novos problemas, novas "verdades" emergem, em um movimento contínuo da história [...]". Desta maneira, tratar da HFC, é tratar da "[...] relação complexa de uma realidade transformadora é tratar de um problema fundamental para a Didática das Ciências que é a formação dos professores [...]" (MORTIMER, 2016 apud IZQUIERDO; AYMERICH; MARTÍNEZ; GATICA et.al., 2016, p. 9).

Afirma ainda, que tratar desta temática é fundamental para os professores em formação, especialmente para aqueles que se encontram na área das ciências da 
natureza. Mostra a relevância destas disciplinas para a construção de novos processos de ensino e aprendizagem de ciências (MORTIMER, 2016 apud IZQUIERDO; AYMERICH; MARTÍNEZ; GATICA et.al., 2016).

Para analisar a visão dos docentes sobre a História e Filosofia da Ciências (HFC) e a Didática da Ciência (DC) no curso de Licenciatura em Química, foi elaborado e aplicado um questionário com 17 questões objetivas e discursivas. O instrumento contempla, na primeira parte, um levantamento do perfil dos docentes de cada campi e, posteriormente, questões relacionadas a relevância e oferta das disciplinas que abordam a HFC.

O questionário foi enviado para os e-mails institucionais para os docentes que atuam no curso de Licenciatura em Química dos campis da IES, totalizando 64 docentes.

Visando a busca por uma participação maior, adotou-se o procedimento de envio do questionário duas vezes por semana durante dois meses. Essa foi uma tentativa de estipular um prazo suficiente para os docentes abrirem suas caixas de mensagens e responder o questionário por meio do link de acesso enviado via e-mail. Apesar disso, como apresentado na tabela abaixo, apenas 37 docentes responderam o questionário.

Tabela 1: Perfil dos professores por Campis da IES

\begin{tabular}{|c|c|c|c|c|c|c|c|}
\hline \multirow[b]{2}{*}{ CAMPIS } & \multirow[b]{2}{*}{$\begin{array}{l}\text { Total de } \\
\text { docentes }\end{array}$} & \multirow{2}{*}{$\begin{array}{c}\text { Professores } \\
\text { participantes }\end{array}$} & \multicolumn{2}{|c|}{$\begin{array}{l}\text { Participantes/ } \\
\text { Sexo }\end{array}$} & \multicolumn{3}{|c|}{ Modalidade que atuam } \\
\hline & & & $\begin{array}{c}\text { Femi } \\
\text { no }\end{array}$ & $\begin{array}{l}\text { Mascul } \\
\text { ino }\end{array}$ & $\begin{array}{l}\text { Ens. } \\
\text { Médio }\end{array}$ & $\begin{array}{c}\text { Ens. } \\
\text { Superior }\end{array}$ & $\begin{array}{l}\text { Ensino } \\
\text { médio e } \\
\text { Ensino } \\
\text { Superior }\end{array}$ \\
\hline A & 8 & 4 & 2 & 2 & - & - & 4 \\
\hline $\mathrm{B}$ & 20 & 14 & 5 & 9 & - & 3 & 11 \\
\hline $\mathrm{C}$ & 9 & 7 & 4 & 3 & - & 1 & 6 \\
\hline $\mathrm{D}$ & 11 & 3 & 1 & 2 & 1 & 1 & 1 \\
\hline $\mathrm{E}$ & 16 & 9 & 4 & 5 & - & 2 & 7 \\
\hline TOTAL & 64 & 37 & 16 & 21 & 1 & 7 & 29 \\
\hline
\end{tabular}

Fonte: Questionário, 2021.

Observa-se que, dos 64 (sessenta e quatro) docentes convidados a participar da pesquisa, apenas pouco mais da metade (37), responderam o questionário na plataforma Google. Mas, apesar do número de abstenções, foi possível levantar dados sobre o perfil dos docentes atuantes nos campis A, B, C, D e E.

Neste perfil, abordou-se ainda, sobre as áreas e níveis de formação de cada um dos docentes, conforme a tabela abaixo.

Tabela 2: Docentes por área e nível de formação 


\begin{tabular}{|c|c|c|c|c|c|}
\hline \multirow{2}{*}{ CAMPIS } & \multirow{2}{*}{ GRADUAÇÃO } & \multicolumn{4}{|c|}{ PÓS-GRADUAÇÃO } \\
\hline & & Especialista & Mestre & Doutor & $\begin{array}{l}\text { Pós- } \\
\text { Doutor }\end{array}$ \\
\hline \multirow{3}{*}{ A } & $\begin{array}{l}\text { Licenciatura em } \\
\text { Química }\end{array}$ & - & - & 2 & - \\
\hline & $\begin{array}{c}\text { Bacharel e Licenciado } \\
\text { em } \\
\text { Química }\end{array}$ & - & - & 1 & - \\
\hline & Bacharel em Química & - & - & 1 & - \\
\hline \multirow{4}{*}{ B } & $\begin{array}{c}\text { Licenciatura em } \\
\text { Química }\end{array}$ & - & 1 & 1 & - \\
\hline & Química industrial & - & - & - & 1 \\
\hline & $\begin{array}{c}\text { Bacharel e Licenciado } \\
\text { em Química }\end{array}$ & - & - & 1 & 1 \\
\hline & Bacharel em Química & - & - & 1 & 1 \\
\hline \multirow{2}{*}{$\mathrm{C}$} & $\begin{array}{l}\text { Licenciatura em } \\
\text { Química }\end{array}$ & $T$ & - & $T$ & - \\
\hline & Bacharel em Química & - & - & 1 & - \\
\hline \multirow{6}{*}{ D } & $\begin{array}{l}\text { Licenciatura em } \\
\text { Química }\end{array}$ & - & 2 & 1 & 1 \\
\hline & $\begin{array}{l}\text { Licenciatura em } \\
\text { Pedagogia } \\
\end{array}$ & - & 1 & - & - \\
\hline & $\begin{array}{l}\text { Licenciatura em } \\
\text { Matemática }\end{array}$ & 1 & - & - & - \\
\hline & $\begin{array}{c}\text { Licenciatura em } \\
\text { Biologia }\end{array}$ & - & - & - & 1 \\
\hline & $\begin{array}{c}\text { Bacharel e Licenciado } \\
\text { em } \\
\text { Química }\end{array}$ & - & - & 1 & - \\
\hline & Bacharel em Química & - & 1 & - & - \\
\hline \multirow{10}{*}{$\mathrm{E}$} & $\begin{array}{l}\text { Licenciatura em } \\
\text { Química }\end{array}$ & - & 1 & 1 & - \\
\hline & Química industrial & - & - & 1 & - \\
\hline & Pedagogia & - & - & 1 & - \\
\hline & Física & - & 1 & 1 & - \\
\hline & Agronomia & - & - & 1 & - \\
\hline & $\begin{array}{c}\text { Química e Farmácia/ } \\
\text { Bioquímica }\end{array}$ & - & 1 & - & - \\
\hline & Letras & - & 2 & - & - \\
\hline & Matemática & - & 3 & - & - \\
\hline & $\begin{array}{c}\text { Bacharel e Licenciado } \\
\text { em } \\
\text { Química }\end{array}$ & - & 1 & - & - \\
\hline & Total: & 2 & $\overline{14}$ & 16 & 5 \\
\hline
\end{tabular}

Fonte: Questionário, 2021

Conforme a tabela 2, a maioria dos docentes são mestres ou doutores. Destes, apenas 12 (doze) docentes são licenciados em química. Os campis A, B, C e D possuem apenas 2 (dois) docentes licenciados em química enquanto que, o campi E possui 4 (quatro), os demais docentes pertencem a outras áreas, apesar de trabalharem com disciplinas no curso de química. 
São poucos os docentes que são licenciados em química ministrando aulas. Visto que o curso é de formação de docentes, pelo fato de serem poucos licenciados, corre-se o risco de acontecer um "desvio bacharelizante da formação" (SÁ; SANTOS, 2016, p. 108), devido aos possíveis incentivos a outros campos de atuação que não seja à docência.

Em relação ao tempo de atuação nos campis, observa-se na tabela 3 o período de trabalho dos docentes na IES.

Tabela 3: Tempo de atuação na IES

\begin{tabular}{|c|c|c|c|c|c|c|c|c|}
\hline \multirow{3}{*}{ CAMPIS } & \multirow{2}{*}{\multicolumn{2}{|c|}{$\begin{array}{l}\text { Professores } \\
\text { participantes }\end{array}$}} & \multicolumn{6}{|c|}{$\begin{array}{c}\text { Tempo de atuação como professor } \\
\text { (por ano) }\end{array}$} \\
\hline & & & \multirow{2}{*}{$<$ de 1} & \multirow{2}{*}{1 a 3} & \multirow{2}{*}{3 a 5} & \multirow{2}{*}{5 a 7} & \multirow{2}{*}{7 a 9} & \multirow{2}{*}{$>$ de 9} \\
\hline & Efetivos & Substitutos & & & & & & \\
\hline A & 4 & & - & - & 1 & 2 & 1 & - \\
\hline B & 7 & & - & 1 & 3 & 2 & - & 1 \\
\hline $\mathrm{C}$ & 3 & & - & - & 1 & - & - & 2 \\
\hline $\mathrm{D}$ & 7 & 2 & 2 & - & 3 & 2 & - & 2 \\
\hline $\mathrm{E}$ & 13 & 1 & - & 2 & 6 & 6 & - & - \\
\hline Total: & 34 & $\overline{3}$ & 2 & 3 & 14 & 12 & 1 & 5 \\
\hline
\end{tabular}

Fonte: Questionário, 2021

Como visto na tabela 3, a maioria dos docentes que atuam nos campis analisados são docentes efetivos e apenas três docentes são substitutos. Nota- se que o tempo de permanência dos docentes nos campis fica entre três a sete anos, o que pode favorecer o trabalho desenvolvido, por proporcionar maior aproximação com os próprios conteúdos ministrados. Inclusive, ao serem questionados sobre a relevância da HFC para o currículo do curso de Licenciatura em Química, 18 (dezoito) professores disseram ser "muito relevante", enquanto 17 (dezessete) apontaram como "relevante", 1 (um) "pouco relevante" e 1 (um) "irrelevante".

Em relação ao nível de relevância para a formação docente, 17 (dezessete) docentes apontaram como "muito relevante", 16 (dezesseis) como "relevantes", 3 (três) como "pouco relevante" e, apenas 01 (um) como "irrelevante". As respostas, nas duas questões, corroboram com o que menciona Penitente (2010, p. 236), quando considera como relevante a HFC na composição do currículo, na elaboração da disciplina e na relação entre o conhecimento problematizado do conteúdo.

Segundo Mattews (1994),

A história e a filosofia podem fazer as idealizações da ciência mais humana, compreensível e explicá-las como útil com direito próprio de ser apreciada. 
Isto é importante para os estudantes a quem se introduz no 'mundo da ciência'. (MATTEWS, 1994, p. 264).

A utilização da HFC e imprescindível ao ensino da química, por se tratar de uma ciência considerada abstrata. Esse tratamento dispensado para a ciência vai interferir diretamente na qualidade do ensino da química, ainda mais quando nos referimos aos cursos de formação docente.

Ao questionarmos sobre a influência da HFC para a "qualidade do ensino de química e para a imagem correta da ciência", 35, dos 39 docentes participantes, reconheceram sua contribuição. Outro item enfatizado no questionário foi acerca da "alfabetização científica". 36 docentes afirmaram que a HFC contribui para esse processo.

Não há dúvida que os professores consideram a HFC necessária e para formação reflexiva do futuro docente pela importância que tem para a promoção dessa alfabetização científica ${ }^{4}$. Além disso, como diz Chassot (2014, p. 62) “[...] seria desejável que os alfabetizados cientificamente não apenas tivessem facilitada a leitura de mundo em que vivem, mas entendessem as necessidades de transformá-lo para melhor”. Esse processo, apesar de não ser fácil, é possível devido a integração da HFC com a DC, porque "possibilita a integração entre a teoria e a prática e desafia a reconsideração dos saberes científicos com vista à apresentação pedagógica" (ALARCÃO, 1996 apud MARQUES, 2015, p. 6).

Com o intuito de verificar se os docentes já possuem alguma experiência com essas disciplinas e, se tiveram alguma dificuldade para ministrá-los, obteve-se as seguintes respostas nove docentes "trabalharam", enquanto 28 "nunca trabalhou" com essas disciplinas. Percebe-se a ausência de experiência com essas áreas do conhecimento, uma vez que a maioria dos docentes são efetivos e estão nos respectivos campis no período entre três a sete anos.

Quanto às dificuldades encontradas pelos nove docentes que já ministraram aulas voltadas a HFC, todos tiveram dificuldades, mesmo que em partes da disciplina, como relatam os docentes:

_ A principal dificuldade é justamente encontrar boas referências e também conscientizar os estudantes da importância das disciplinas de História e

${ }^{4}$ Chassot (2014, p. 62), "considera a alfabetização científica como o conjunto de conhecimentos que facilitariam aos homens e mulheres fazer uma leitura do mundo onde vivem". 
Filosofia da Ciência como ferramentas para a compreensão da ciência no mundo atual (DOCENTE A).

_ Bibliografia atualizada e o interesse dos alunos em temas históricos e filosóficos, uma vez que acreditam ser necessário apenas os conhecimentos específicos, apesar de não ser a maioria (DOCENTE B).

- Falta de conhecimento prévio dos discentes (DOCENTE C). (QUESTIONÁRIO, 2018).

Conforme exposto pelos docentes, a falta de referência e a bibliografia atualizada são as principais dificuldades e esse fato é reiterado por Martins (2006 apud Pereira, 2009, p. 90), ao dizer que, "a carência de material didático adequado, os equívocos sobre a natureza da $\mathrm{HC}$ e do seu uso na educação e a falta de docentes formados no campo da disciplina", comprometem o trabalho docente. Outra dificuldade relatada por um dos docentes foi a falta de preparo. Tanto a falta de material quanto a falta de preparo do docente está elencado a ausência de disciplinas de HFC e DC nos currículos que também acontece nos campis pesquisados. Consequentemente, vão despertar um restrito interesse por pesquisas sobre essas temáticas. Desta maneira, "os cursos de licenciatura ainda continuam impregnados pelos modelos academicista e tecnicista"' (PEREIRA, 2009, p. 34).

Neste aspecto é "que a filosofia e história da química tornam-se urgentes e podem fornecer subsídios teóricos para contextualizar as explanações, tornando o ensino de química significativo e real", como afirma (KAVALEK, SOUZA e DEL PINO et al. 2015, p. 3).

Assim, a característica e influência da HFC e da DC, podem auxiliar diretamente na prática docente, evitando situações como a que foi relatada:

_Como professor de física tenho percebido que os estudantes têm se preocupado em apenas apresentar uma resposta numérica. Eles se quer apresentam dúvidas ou questionamento a respeito da formulação do método. Em nenhum momento apresentam ter uma compreensão quanto as mudanças e alterações nas questões científicas. Hoje, a preocupação deles é apenas resolver exercícios (DOCENTE D). (QUESTIONÁRIO 2018).

Como foi visto no início deste trabalho, quando inseridas nos currículos, a HFC e a DC passam a contribuir para a superação da falta de significação das aulas promovendo mais compreensão dos conteúdos, além de despertar o alunado para a análise e a reflexão, ausentes no relato acima descrito. 
Percebe-se que as dificuldades encontradas, quando disciplinas relacionadas à HFC são ministradas, também estão relacionadas a formação dos professores, como descrito nos depoimentos:

_ A parte de filosofia exigiu mais dedicação no preparo devido a deficiência durante minha formação (DOCENTE E).

_ Organizar as ideias e envolver mais os alunos nas atividades de leitura e discussão dos textos (DOCENTE F). (QUESTIONÁRIO, 2018).

Verifica-se que os princípios filosóficos estão ausentes na própria formação dos docentes. O primeiro admite a deficiência na sua própria formação, enquanto o outro não consegue promover um debate necessário para a construção do conhecimento científico. Esses fatos reafirmam a necessidade dos docentes estar preparado: "Um professor de ciências instruído pela história e filosofia pode ajudar os estudantes a entender como a ciência capta, ou não capta, o mundo real" (MATTEWS, 1994, p. 264).

Caso os cursos contemplassem a HFC e a DC de uma forma mais efetiva, a própria formação dos docentes que ministram disciplinas relacionadas, teriam maior preparo em sala de aula.

Por fim, esta discussão sobre a HFC que está presente no ensino de ciências, ou seja, na DC, não é recente e nem vai terminar aqui. Ao contrário, é preciso enfocar cada vez mais a temática. Como menciona Sherratt (1983 apud MATTEWS, 1994),

\footnotetext{
A defesa da importância da HFC para professores de ciências não é nova. As páginas iniciais de um texto de 1929 para professores de ciências descreve o professor, com êxito, como aquele que: "conhece o seu próprio conteúdo [...] é amplamente instruído em outros ramos da ciência [...] sabe como ensinar [...] é capaz de expressar-se com lucidez [...] é hábil manipulando [...] tem recursos tanto para as demonstrações teóricas como para o laboratório [...] é um lógico [...] é algo filosófico [...] é tão bom historiador que pode sentar-se com um grupo de alunos e falar de equações, a vida dos trabalhos pessoais de gênios tais como Galileo, Newton, Faraday e Darwin (SHERRATT, 1983 apud MATTEWS, 1994, p. 266).
}

Este seria o ideal para os docentes na atualidade. O enfoque curricular, a conscientização das próprias necessidades e o reconhecimento da relevância da HFC e da DC, pode ser o início de muitas transformações.

\section{CONCLUSÕES}

Mesmo que as discussões sobre a HFDC tenham ganhado forças entre a comunidade científica, ao atingirmos o objetivo da pesquisa de fazer uma análise dos 
currículos das licenciaturas em química, dos campis de uma IES, localizada no centro oeste brasileiro, verificando a existência e relevância da HFC.

Percebe-se a ausência das disciplinas de HFC e DC também na graduação dos docentes que atuam nos campis analisados. No questionário aplicado aos docentes, os relatos obtidos foram de que não tiveram disciplinas voltadas efetivamente a HFDC. Inclusive, mencionaram que o fato de não terem tido essa formação acaba gerando dificuldades no trabalho com disciplinas relacionadas à essas áreas. Essa ausência da HFDC na formação dos próprios docentes "pode" ser um dos fatores que dificultam a implantação dessas disciplinas nos currículos, pois ainda falta formação docente para sua efetivação.

Desta maneira, faz-se necessário, portanto, repensar os currículos, proporcionar maior enfoque à HFDC visando uma formação mais completa dos futuros docentes, uma vez que necessitarão dessas áreas para o ensino da química. Além disso, como foi mencionado durante a pesquisa, quando não atribuímos a relevância necessária dessas disciplinas científicas, não conseguimos promover efetivamente uma alfabetização científica. Como menciona Chassot (2014, p. 63), é preciso considerar a "ancestralidade nos alquimistas medievos", ou seja, como professor de química não é possível que se tenha um conhecimento limitado, apenas específico. Para se compreender o mundo é primordial saber sua origem e funcionamento. Para ensinar química é preciso conhecer sua história, refletir sobre ela enquanto ciência e saber transpor os conhecimentos que dela originaram, sem distorções ou interpretações errôneas ou superficiais. Se os currículos dos cursos de licenciatura em química conseguir promover e despertar esse espírito científico, não haverá nenhum “obstáculo epistemológico" (BACHELARD, 1996, p. 16), para promover e/ou ensinar química e, desperta-se a consciência, que sua imagem, enquanto ciência, depende disso.

\section{REFERÊNCIAS}

ADÚRIZ-BRAVO, A.; IZQUIERDO, M.; ESTANY, A. Una propuesta para estructurar la enseñanza de la filosofía de la ciencia para el profesorado de ciencias en formación. Electrónica de Enseñanza de las ciencias, v. 20, n. 3,p. 465-476, 2002.

ALARCÃO, 1996 apud MARQUES, D. M. Formação de professores de ciências no contexto da história da ciências. História da Ciência e Ensino, v. 11, p. 1-17, 2015.

AYMERICH, M. I.; MARTÍNEZ, Á. G.; GATICA, M. Q.; ADÚRIZ-BRAVO, A. Historia, filosofía y didáctica de las ciencias: aportes para la formación del profesorado de ciências. Bogotá: Universidad Distrital Francisco José de Caldas, 2016. 
BACHELARD, G. A formação do espírito científico: contribuição para uma psicanálise do conhecimento. 5. ${ }^{a}$ reimpressão. Trad. Esteia dos Santos Abreu. Rio de Janeiro: Contraponto, 1996.

CHASSOT, A. Alfabetização científica: Questões e desafios para a educação. 6.ed. Ijuí: Unijuí, 2014.

GERHARDT, T. E.; SILVEIRA, D. T. Métodos de Pesquisa. 1. a ed., Porto Alegre: UFRGS, 2009.

GIL, A. C. Como elaborar projetos de pesquisa. 4. ed. São Paulo: Atlas, 2002, 192p.

GONÇALVES, E. A. A filosofia da ciência e a didática da ciência na formação de professores. João Pessoa: IV CONEDU, 2017.

IZQUIERDO-AYMERICH, M.; ADÚRIZ-BRAVO, A. et al. Historia, filosofia $\mathbf{y}$ didáctica de las Ciencias: Aportes para la formación del profesorado de ciências. 21. ed. Colombia: Universidad Distrital Francisco José de Caldas, 2016.

KAVALEK, D. S.; SOUZA, D. O.; DEL PINO, J. C.; RIBEIRO, M. A. P. Filosofia e História da Química para educadores em Química. História da Ciência e Ensino, v. 12, p. 1-13, 2015.

LABARRERE; QUINTANILLA, 2002 apud FERNÁNDEZ, L. C.; GRATCA, M. Q.; BLANCAFORT, A. M. La impotancia de la historia de la química en la enseñanza escolar: Análise del pensamento y elaboración de material didáctico de professores em formación. Ciência e Educação, v. 16, n. 2, p. 277-291, 2010.

LOPES, A. C. Currículo e epistemologia. Ijuí: Unijuí, 2007.

MARQUES, D. M. Formação de professores de ciências no contexto da história da ciências. História da Ciência e Ensino, v. 11, p. 1-17, 2015.

MATTEWS, M. R. Historia y epistemología de las ciencias. Historia, filosofia y enseñanza de las ciencias: la aproximación actual. Enseñanza de las ciencias, v. 12, n. 2, p. 255-277, 1994.

MORTIMER, 2016 apud IZQUIERDO-AYMERICH, M.; MARTÍNEZ, Á. G.; GATICA, M. Q. Historia, filosofía y didáctica de las ciencias: aportes para la formación del profesorado de ciencias. Bogotá: Universidad Distrital Francisco José de Caldas, 2016.

PENITENTE, L. A. A.; CASTRO, R. M. A história e filosofia da ciência: contribuições para o ensino de ciências e para a formação de professores. Revista Brasileira de Ensino de Ciências e Tecnologia, v. 2, n. 4, 2010.

PEREIRA, G. J. S. A. História e Filosofia da Ciência nos Currículos das Licenciaturas em Física e Química da UFRN. Dissertação de mestrado. 235 f. Natal: Universidade Federal do Rio Grande do Norte, 2009.

SÁ, C. S. S.; SANTOS, W. L. P. Motivação para carreira docente e construção de identidades. Revista Química Nova, v. 39, n. 1, p. 104-111, 2016. 
SILVA, R. R.; SOBREIRA, A. C. M.; ABREU, A. R. MOTA, E. F.; MARTINS, M. M. C. A importância da filosofia no ensino das ciências na percepção dos professores do ensino fundamental. Anais... IV CONEDU, 2017.

TORRES, A. P. G.; BADILLO, R. G. Historia, epistemologia y didáctica de las ciências: unas relaciones necessárias. Cundinamarca, v. 13, n. 1, p. 94, 2007.

Recebido em: 03/01/2022

Aprovado em: 23/01/2022

Publicado em: 26/01/2022 